TINGGALAN MEGALITIK BATU SUKUN MENGUNGKAP CERITA RAKYAT DI KAMPUNG YAPASE

(The Remains of the Sukun Stone and Folklore in Yapase Village)

\title{
Rini Maryone
}

Balai Arkeologi Papua

Jalan Isele, Kampung Waena, Distrik Heram, Kota Jayapura 99358

e-mail: rinimaryone1972@gmail.com

\section{INFO ARTIKEL}

\section{Histori Artikel}

Diterima : 25 Maret 2019

Direvisi : 5 April 2019

Disetujui : 28 Juni 2019

Keywords:

Sukun stone, folklore, Yepase village

\section{Kata Kunci:}

Batu sukun, cerita rakyat, Kampung Yapase

\section{ABSTRACT}

This article examines the remains of the sukun stone and folklore in Yapase Village. The purpose of this paper is to reveal the Yakarmilena folklore and cultural values contained in the sukun stone folklore. The method used is a qualitative method, with inductive reasoning. The results of the study were nine sukun stones, consisting of one large stone which was a mother's stone and one stone in the shape of a statue as a girl, while six other oval-shaped stones were a pillow, and one flat rock was a plate of offerings. Archaeological remains of sukun stones in Kampung Yabase serve as a place to perform religious ceremonies to ask for blessings from the ancestors. From the folklore stone sukun has noble values, including cultural values, conceptualization values, social values and religious values.

\section{ABSTRAK}

Tulisan ini mengkaji tinggalan megalitik batu sukun dan cerita rakyat di Kampung Yapase . Tujuan penulisan ini adalah dapat mengungkapkan cerita rakyat suku Yakarmilena dan nilai-nilai budaya yang terkandung dari cerita rakyat batu sukun. Metode yang di gunakan adalah metode kualitatif, dengan penalaran induktif. Hasil penelitian berupa sembilan buah batu sukun, terdiri dari satu batu yang berukuran besar merupakan batu ibu dan satu buah batu yang berbentuk arca sebagai anak perempuan, sedangkan enam buah batu berbentuk lonjong lainnya merupakan bantal, dan satu buah batu ceper bercekungan merupakan piring tempat persembahan. Tinggalan arkeologi batu sukun di Kampung Yabase dijadikan sebagai tempat melakukan upacara keagamaan untuk meminta berkah kepada leluhur. Dari cerita rakyat batu sukun ini memiliki nilainilai luhur, diantaranya nilai budaya, nilai konseptualisasi, nilai sosial dan nilai religi. 


\section{PENDAHULUAN}

Megalitik adalah sebuah budaya yang pernah berkembang pada masa lalu, sekarang tradisi tersebut masih banyak dianut oleh berbagai suku bangsa, termasuk di suku-suku yang berada di Papua. Megalitik mengandung arti mega = besar dan lithit = batu, sehingga lebih mudah untuk mengatakan suatu budaya batu besar yang memanfaatkan batuan alam sebagai salah satu simbol tentang alam dan sistem kepercayaan suatu suku bangsa tertentu. Pengusung kebudayaan tersebut, memanfaatkan batu-batu besar sebagai sarana dan media untuk melakukan pemujaan nenek moyangnya (Lelono 2015 : 179).

\section{McMillan Brown (1907)}

menyatakan bahwa kebudayaan megalitik masuk ke Indonesia dibawa oleh ras Kaukasia yang datang dari daerah Mediterania melalui Benua Asia bagian selatan (Mulia, 1981 : 2). Beberapa ahli menyatakan pendapatnya berbeda-beda mengenai masuknya kebudayaan megalitk di Indonesia.

Sedangkan tradisi megalitik (living megalithic) di Indonesia dapat ditemukan di beberapa wilayah antara lain terdapat di Nias, Toraja, Sumba, dan Flores (Geldern, 1984 : 306-312), dan termasuk di wilayah Papua, untuk luar Indonesia tradisi megalitik berlanjut ini terdapat di daerah Assam, Birma, Serawak (Heekeren, 1958 : 44), Kepulauan Luzon (Philipina) serta Siam Utara (Wales, 1958).

Papua menerima pengaruh megalitik dari Asia Tenggara lewat rute barat melalui kepulauan Indonesia bagian selatan, Maluku, selanjutnya memasuki Kepala Burung; dan pengaruh megalitik juga menyebar melalui Mikronesia, sebelum menuju ke barat menuju Sepik di Papua Nugini melalui Filipina, Sulawesi Utara, dan Halmahera (Soejono, 1994 : 30).

Megalit di Papua berbeda dengan bentuk megalit yang ditemukan di wilayah Indonesia bagian barat dan sebagian Indonesia bagian timur (Sulawesi Tengah, dan Utara). Megalit di Papua lebih dicirikan oleh pola yang sederhana yang mirip dengan bentuk-bentuk yang ada di Indonesia bagian Timur seperti, Maluku dan Nusa Tenggara Timur (Prasetyo, 2011 :88).

Persebaran unsur-unsur megalitik juga ditemukan di Papua. Riesenfeld pada tahun 1950 pernah melaporkan kehadiran kubur-kubur batu, tembok-tembok batu serta tempat persajian yang tersebar pada beberapa pulau kecil di Adi, Namatota, Patipi, Fu-um, Ora, Batanta, Sorong dan Numfor, serta pantai dan Sungai Karufa di sebelah barat sekitar di Skroe, Sisir dan Bintuni, serta di sekitar Danau Sentani (Riesenfeld 1952 : 405-447 dalam Galis, $1957: 342$ ).

Tradisi megalitik di Papua merupakan kegiatan ritual dengan menggunakan medium batu-batu alam seperti stalagmit dan stalagtit dalam gua-gua, dolmen, batu pahatan dan batubatu alam lainnya yang dianggap sebagai jelmaan roh-roh nenek moyang. Yang 
dilakukan baik secara perorangan dan kelompok. Kegiatan ritual ini menunjukkan adanya tradisi berlanjut dan sekaligus dapat menggambarkan sistem religi masa lampau orang Papua yang masih bertahan ditengah kehidupan masyarakat pemeluk agama Kristen dan Islam. Kegiatan ritual tersebut merupakan beberapa tindakan, seperti: berdoa, bersujud, bersaji, berkorban, makan bersama, menari dan menyanyi, berprosesi, berseni, drama suci, berpuasa, bertapa dan bersemedi. Bentuk kegiatan ritus tersebut nampak pada tradisi kepercayaan megalitik pada beberapa suku-suku yang ada di Papua, baik yang ada di pesisir maupun di pegunungan Papua termaksud juga pada suku-suku di pesisir Demta, dan Depapre.

Peninggalan megalit di pesisir Depapre terkait dengan cerita rakyat mengenai pemandian batu sukun, merupakan cerita rakyat yang diceritakan turun-temurun, dari generasi ke generasi. Pengertian cerita rakyat itu sendiri adalah prosa sastra lisan yang dilahirkan oleh masyarakat dan persebarannya atau pewarisannya dilakukan dengan cara lisan/ dari mulut ke mulut. Dalam cerita rakyat ini banyak ditemukan hal-hal yang kadangkadang tidak dapat dipahami oleh logika manusia. Menurut Wiliam R. Bascom (ahli folklore dari Amerika Serikat) cerita rakyat dapat diklasifikasikan ke dalam tiga golongan, yaitu mite (myth), legenda (legend) dan dongeng (folktale) (Danandjaya, dalam Ria Lestari, 2012 : 21).

Begitu pulah cerita rakyat pada tinggalan megalitik (batu sukun) adalah cerita pada masa lampau yang menjadi ciri khas suku, khususnya pada suku Yakarmilena di Distrik Deprare ini. Cerita rakyat ini memiliki kultur budaya yang mencakup kekayaan budaya dan sejarah yang dimiliki masing-masing suku-suku bangsa di dunia (Abhasshare.blogspot. com).

Cerita rakyat mempunyai kegunaan dalam kehidupan bersama, sebagai alat pendidik, hiburan, protes sosial dan proyeksi suatu keinginan yang terpendam. Sedangkan cerita rakyat bersifat pralogis yaitu logika yang khusus dan kadang berbeda dengan logika umum. Penelitian tentang cerita rakyat telah banyak dilakukan untuk berbagai macam tujuan. (Danandjaja dalam Ria lestari 2012 : 21).

Nilai dalam cerita prosa rakyat, baik lisan maupun tulisan merupakan unsur esensial dari sebuah cerita prosa rakyat itu secara keseluruhan. Oleh karena itu mengungkapkan nilai-nilai yang terdapat dalam cerita rakyat, secara tidak langsung akan memberikan pengertian latar belakang sosial budaya masyarakat pendukungnya, yang ceritanya tumbuh dan berkembang serta diterima dan dipedomani oleh masyarakat pendukungnya (Roesmana, 2012 : 300).

Cerita rakyat dapat digali dari berbagai sumber, salah satu sumber yang penulis pakai di sini adalah berasal dari tinggalan megalitik yaitu batu-batu alam yang disebut menhir dan batu arca. Dalam penulisan ini akan diangkat cerita rakyat, dari tinggalan megalitik (batu sukun) yang terdapat di Kampung Yapase. 
Untuk memudahkan alur berpikir, kerangka pikir yang penulis gunakan adalah tinjauan pustaka yang relevan dengan penulisan ini yaitu dimana penelitian tentang mengungkapkan cerita rakyat berdasarkan temuan purbakala di Gua Sosoraweru di Kampung Forir, Distrik Kokas, Kabupaten Fakfak. Dalam penelitiannya ada beberapa temuan benda purbakala berbentuk menhir (batu tegak) dari bahan batu gamping (limestone). Menhir tersebut berjumlah 4 buah; 3 buah berukuran 150 × 75 × 40 × $20 \mathrm{~mm}, 1$ buah lainnya berukuran $50 \times 40 \times 20 \mathrm{~mm}$, dari temuan purbakala tersebut diduga memiliki asal-usul yang diceritakan dalam cerita rakyat suku Baham (Maryone, 2014 : 113-120). Konsep pemikiran inilah yang melatar belakangi penulisan ini dimana ada temuan megalitik di pesisir Demta berupa tinggalan batu Sukun di Kampung Yepase, yang juga dapat mengungkapkan cerita rakyat suku di pesisir ini.

PenelitianinidilakukandiKampung Yapase, di Distrik Depapre, Kabupaten Jayapura. Penelitian ini menggunakan metode kualitatif, tidak memakai prosedur statistik atau bentuk hitungan lainnya. Alasan menggunakan metode kualitatif diantaranya karena fenomena budaya dalam kehidupan masyarakat terkadang tidak bisa dipahami secara mendalam kalau tidak menggunakan metode kualitatif ini. Misalnya unsur sejarah, tingkah laku, dan aktivitas sosial lainnya, sehingga fenomena yang lebih tepat jika menggunakan penelitian kualitatif.

Dalam penulisan ini pula menggunakan dua jenis data yakni data primer dan data sekunder. Data primer ialah data yang diperoleh dari lapangan melalui observasi lapangan terhadap objek yang diteliti yaitu tinggalan megalitik (batu sukun) dan cerita rakyat. Dalam observasi lapangan ini tidak lupa juga dilengkapi dengan wawancara. Wawancara dilakukan dengan beberapa narasumber guna mendapat informasi tentang tinggalan megalit (batu sukun) dan cerita rakyat tersebut. Data sekunder yaitu data yang diperoleh melalui studi kepustakaan, yakni melakukan pengumpulan data tertulis yang berhubungan dengan penulisan mengenai tinggalan megalitk dan cerita rakyat, dari referensi buku-buku yang berkaitan dengan tinggalan megalitk dan cerita rakyat yang ada di Indonesia. Selain melakukan pengumpulan buku-buku yang berkaitan dengan tinggalan megalit dan cerita rakyat juga dilakukan penelusuran lewat internet, sehingga data-data tersebut dapat dikaji sebagai langkah awal dalam mempersiapkan kerangka pemikiran yang berhubungan dengan penulisan ini.

Dalam interpretasi, penelitian ini menggunakan penalaran induktif sebagai pola pikir dalam merumuskan jawaban masalah yang telah diajukan. Penalaran induktif bergerak dalam kajian faktafakta atau gejala-gejala khusus kemudian disimpulkan sebagai gejala yang bersifat umum atau generalisasi impiris (Tanudirdjo, 1988-1989 : 34 dalam Darojah 2013 : 35) dengan penalaran induktif diharapkan budaya masa lampau dapat direkontruksi lewat data etnografi dari tradisi masyarakat 
yang masih berlangsung (pendekatan Etnoarkeologi).

\section{PEMBAHASAN}

Kampung Yapase, Distrik Depapre termasuk dalam wilayah administrasi kabupaten Jayapura. Secara geografis wilayah Kabupaten Jayapura terletak pada posisi $1^{\circ}-3^{\circ} \mathrm{LS}, 137^{\circ}-141^{\circ} \mathrm{BT}$. Luas wilayah $17.516,6 \mathrm{~km}^{2}$. Batas wilayah Kabupaten
Jayapura adalah sebagai berikut: Sebelah utara berbatasan dengan Samudera Pasifik dan Kabupaten Sarmi. Sebelah selatan bebatasan dengan Kabupaten Pegunungan Bintang, Kabupaten Yahukimo dan Kabupaten Tolikara. Sebelah barat berbatasan dengan Kabupaten Sarmi. Sebelah timur berbatasan dengan Kota Jayapura dan Kabupaten Keerom (http:// www.jayapurakab.go.id/)

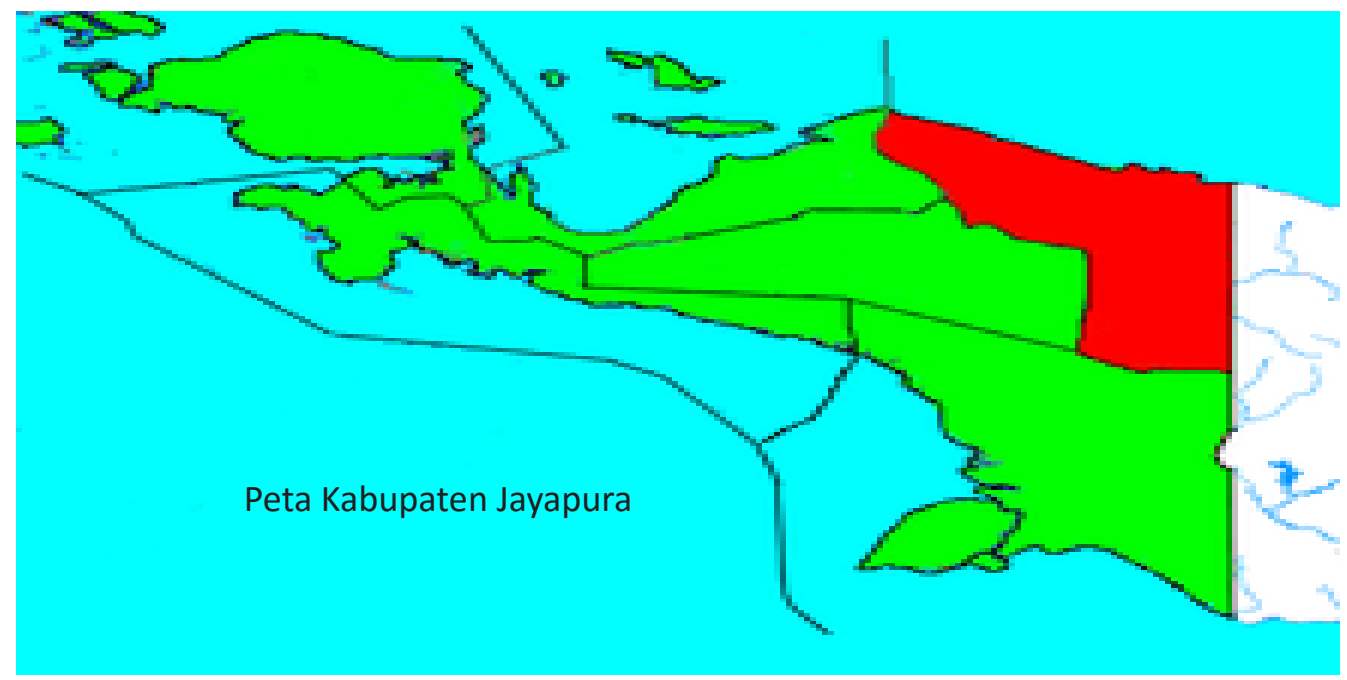

Di Kampung Yepase telah garispinggirwajah dari kening hingga dagu. ditemukan batu sukun (merawai) yang Mata dan hidungnya sudah aus sehingga terletak di pesisir pantai pada koordinat $\mathrm{S}$; tidak terliha, telinganya memakai anting020 26'56.2” dan E : 1400 36’07.1. Batu sukun adalah sejumlah batu dari berbagai ukuran dan bentuk yang tertata dalam satu area seluas 2,60 meter x 2,60 meter. Batubatu tersebut terdiri atas batu ibu berupa monolit berbentuk seperti wajik atau jajaran genjang dengan permukaan yang tidak rata. Disamping itu, terdapat sebuah arca menhir dengan bentuk kepala lonjong dan memakai topi kerucut dan ikat kepala melingkar di dahi. Pada wajahnya yang lonjong terdapat seperti ikatan tali pada anting bergelompang yang terjuntai hingga kebahu, ujung dagunya panjang hingga dada dan menutupi bagian leher. Bagian dada arca tersebut tidak teridentifikasi,tetapi tampaknya menggunakan pakaian karena pada bagian lengan terdapat lekukanlekukan seperti kain yang menjuntai. Pinggangnya memakai ikat pinggang. Pada bagian ginital terdapat gambar segitiga, pada bagian bawah tergambar batasan berupa garis melingkar, sedangkan pada bagian samping dan belakang arca 
terdapat lekukan-lekukan pakaian yang menjuntai seperti lekukan kain di bawah leher dan pinggang. Bentuk kaki arca tidak diketahui karena keadaan bagian bawahnya mengerucut, mungkin karena aus atau memang demikian adanya. Kemungkinan lain karena posisi arca pada waktu lampau tidak dalam keadaan terlentang atau tidur di atas tanah, tetapi ditancapkan berdiri di atas tanah. Menurut masyarakat, arca ini adalah seorang anak perempuan (Merweri) yang menjadi sumber berkat buah sukun. Selain itu terdapat delapan buah menhir berbentuk lonjong dengan permukaan halus yang tersusun melintang di atas permukaan tanah dengan orientasi timur barat-utara selatan. Terdapat pulah sebuah piring batu (betew) yang telah pecah dan bagian yang pecah telah hilang. Pada bagian batu yang tersisa tampak pada permukaan tiga cekungan berbentuk lonjong. Salah satu diantara cekungan itu masih utuh, sedangkan dua cekungan lainnya tinggal sebagian karena pecah. Piring batu tersebut berfungsi sebagai tempat persembahan (Djami, 2017 : 38).

Dari peninggalan batu sukun yang sudah diuraikan di atas mempunyai cerita tersendiri bagi keturunan Yakarmilena. Cerita tersebut diceritakan kembali oleh keturunan ini, berikut ini kisah mengenai peninggalan batu sukun:

Cerita tentang batu sukun terkait dengan tradisi memanggil buah sukun supaya berbuah lebat dan panen melimpah. Pada mulanya ditempat ini tidak ada pohon sukun hingga datanglah nenek moyang Yakarmilena dari daerah timur Nafri dengan membawa buah sukun bersamanya. Buah sukun yang dibawa tersebut kemudian ditanam di lokasi Batu Sukun berada. Pohon sukun yang tumbuh dari buah tersebut menjadi besar dan menghasilkan buah yang banyak, besar-besar dan enak rasanya. Singkat cerita, nenek moyang mereka melahirkan seorang anak perempuan yang diberi nama Merawai. Ibu dan anak ini kemudian berubah menjadi batu. Arca menhir ini dipercaya membawa rezeki buah sukun. Pada setiap bulan musim sukun, keluarga keturunan Merawai, yaitu keluarga Yakarmilena, biasanya melakukan upacara pemanggilan buah sukun dengan cara memandikan arca Merawai di atas batu ibu, upacara ini hanya boleh dilakukan oleh keluarga Yakarmilena. Selain itu upacara ini dapat terjadi atas permintaan masyarakat lain untuk memberkati pohon sukun di kebun mereka (Djami, 2017 : 40-41).
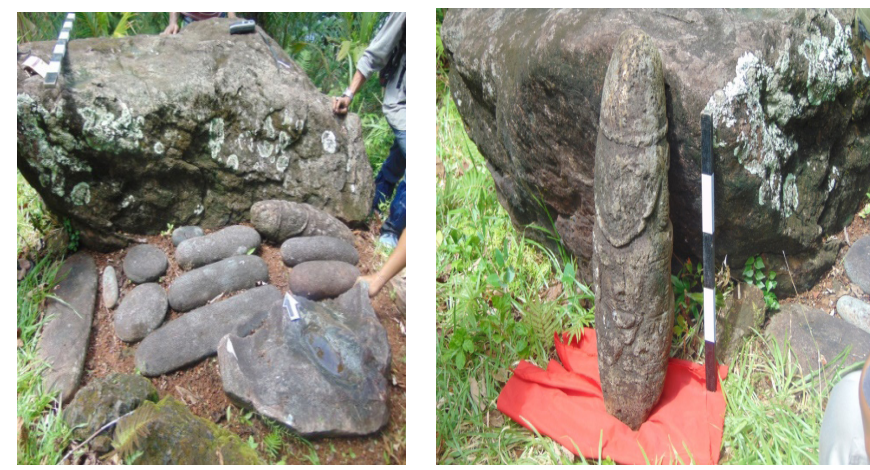

Foto 1. Batu Sukun-Arca Menhir (dokumentasi Balai Arkeologi Jayapura) 
Dari uraian cerita batu sukun tersebut, ada khasanah nilai budaya yang tersirat, dan pesan moral yang dapat dipetik diantaranya:

\section{Nilai budaya}

Nilai budaya yang terkandung dalam cerita rakyat batu sukun ini berkaitan dengan etos kerja yang meliputi kerja keras, ketekunan, ketaatan, dan kesabaran. Dalam kisah cerita batu sukun ini moyang dari Yakarmilina bekerja keras, tekun, taat dan sabar, menanam buah sukun sehingga dengan kerja kerasnya ia dapat memiliki pohon sukun yang terbaik, memiliki buah yang enak rasanya. Sehingga pohon sukun tersebut dapat dinikmati oleh seluruh kampung bahkan kampung-kampung yang berada disekitarnya.

\section{Nilai sosial}

Nilai sosial yang tercermin dari cerita batu sukun ini, yang diyakini oleh masyarakatnya bahwa cerita tempat batu sukun ini benar-benar ada. Arca menhir ini dipercaya membawa rezeki melalui buah sukun ini. Dengan melakukan upacara pemanggilan buah sukun dengan cara memandikan arca Merawai di atas batu ibu. Nilai sosial yang bisa di ambil yaitu dapat memberi kesejahteraan kepada orang banyak.

\section{Nilai Konseptualisasi}

Nilai konseptual yang dimaksud adalah pengertian, pendapat atau penafsiran akan sesuatu yang mungkin terjadi. Demikian halnya dalam cerita batu sukun ini dalam konseptualisasi bahwa manusia hidup sangat saling ketergantungan, baik antar individu maupun manusia dengan alam sekitar. Kesadaran akan pentingnya alam sekitar seperti halnya peran sebuah pohon pada kehidupan manusia memberi kehidupan pada manusia, namun sebaliknya bila pohon sukun tidak dijaga tidak dilestarikan maka pohon tersebut akan punah dan tidak menghasilkan apaapa bagi kehidupan manusia itu sendiri. Namun bila pohon sukun tersebut terurus dengan baik, maka pohon sukun tersebut dapat memberi kesejahteraan kepada masyarakat di sekitarnya. Hikmah yang dipetik oleh masyarakat, yakni kesadaran akan pentingnya memelihara serta melestarikan alam sekitarnya dan hal yang mutlak diperlukan. Kelangsungan hidup manusia yang harmonis dengan alam sekitar merupakan sebuah harapan dan cita-cita kita semua.

\section{Nilai Religi}

Selain itu cerita batu sukun memiliki nilai religius, yakni masyarakat percaya akan adanya kekuatan gaib atau roh nenek moyang yang mendiami batu sukun tersebut. Mereka percaya dengan mengadakan ritual memandikan batu sukun ini buah sukun merekapun akan diberkati. Dengan menghasilkan buah sukun yang terbaik, besar-besar dan rasanya enak, seperti buah sukun dari keluarga Yakarmilena.

Dari cerita tersebut merupakan inspirasi yang menarik untuk dieksplor 
dan diekspos pada khalayak umum sebagai khasanah pengembangan ilmu budaya, yang merupakan perbendaharaan pemikiran warisan nenek moyang yang berguna juga untuk masa sekarang yang juga sebagai alat pendidik kepada masyarakat.

Pentingnya mengkaji nilai-nilai yang terkandung dalam cerita rakyat karena cerita rakyat itu memiliki fungsi kultural. Lahirnya suatu cerita rakyat bukan semata-mata di dorong oleh keinginan penutur untuk menghibur masyarakatnya melainkan dengan penuh kesabaran ia ingin menyampaikan nilai-nilai luhur kepada generasi penerusnya.

Keberadaanceritainimemilikiperan yang penting, salah satunya terkandung nilai-nilai budaya, sosial, konseptualisasi dan religi. Nilai-nilai inilah yang memberikan gambaran dan pengalaman tersendiri pada masyarakat.

\section{PENUTUP}

Tinggalan arkeologis di Kampung Yabase berbentuk batu arca yang berjumlah sembilan buah batu sukun, terdiri dari satu batu yang berukuran besar merupakan batu ibu dan satu buah batu yang berbentuk arca sebagai anak perempuan, sedangkan enam buah batu berbentuk lonjong lainnya merupakan bantal, dan satu buah batu ceper bercekungan merupakan piring tempat persembahan. Tinggalan arkeologis tersebut dapat mengungkapkan cerita rakyat suku Yakarmilena. Tinggalan arkeologi batu sukun di Kampung Yabase dijadikan sebagai tempat melakukan upacara keagamaan untuk meminta berkah kepada leluhur, yang merupakan tradisi wadah penguatan jati diri dan dipandang sebagai bagian penting dalam kehidupan, diyakini bahwa roh leluhur memiliki kekuatan sakti atau suci di masa lampau. Dari cerita rakyat batu sukun ini memiliki nilai-nilai luhur, diantaranya : nilai budaya, nilai konseptualisasi, nilai sosial dan nilai religi. Nilai-nilai luhur tersebut yang dapat membangun karakter bangsa yang beraklak mulia, sebab dengan menhir batu sukun dan cerita rakyat ini, mereka menyakini bahwa media batu sukun tersebut dapat menghubungkan manusia dengan leluhurnya agar senantiasa memberikan berkat yang melimpah dan dapat menolong dalam menghadapi kesulitan hidup. 


\section{DAFTAR PUSTAKA}

Endiraswara, Suwardi (editor). 2013. Folklor Nusantara, Hakikat Bentuk, dan Fungsi. Yogyakarta: Penerbit Ombak.

Djami, Erlin Novita Idje. 2017. Tipologi dan MaknaTinggalan Megalitik di Pesisir Pantai Utara Kabupaten Jayapura dalam Jurnal Penelitian dan Pengembangan Arkeologi Amerta Vol. 35 No 1 Juni. Pusat Penelitian Arkeologi Nasional.

Galis, K. W. 1957. “Oude Fortificatie Ontdekta” New Guinea Studien III.

Hoop, A. N. J. Th. Van der. 1932. Megalithik Remains in South Sumatra. Tranlated by W. Shirlaw, Zuthpen. W. J. Thieme \& Cie.

Lelono Hari. T. M. 2015. Pemukiman Tengger Bertradisi Megalitik dalam Pernak-Pernik Megalitik Nusantara. Yogyakarta: Galangpress.

Lestari, Ria Fatimah Ummu. 2012. Mengungkapkan Cerita Rakyat Berdasarkan Temuan Purbakala di Pulau Ormu, Kabupaten Jayapura. Jurnal Penelitian Arkeologi Papua dan Papua Barat. Balai Arkeologi Jayapura.

Maryone, Rini. 2014. Megalitik dan Cerita Rakyat Suku Bahan di Gua Sosoraweru FakFak. Jurnal Arkeologi Papua Vol 6 Edisi No 2 November. Balai Arkeologi Papua.

Mulia, Rumbi. 1981. The Only Order Megalithic Tradition in Indonesia. Bulletin of The Research Center of Archaelogy of Indonesia, No.16. Jakarta.

Rosmana, Tjetjep. 2012. Kearifan Tradisional dalam Cerita Rakyat Masyarakat Sumedang. Patanjala, Jurnal Penelitian Sejarah dan Budaya Vol. 4. No. 2 Juni. Balai Pelestarian Sejarah dan Nilai Tradisional Bandung.

Prasetyo, Bagyo. 2011. Budaya Pantai dan Pedalaman Masa Prasejarah di Papua dalam Austronesia dan Melanesia di Nusantara, mengungkapkan Asal-usul dan Jati diri dari Temuan Arkeologis. Yogyakarta: Penerbit Ombak kerjasama dengan Balai Arkeologi Jayapura.

Soejono, R. P. 1984. Prasejarah. Sejarah Nasional Indonesia I. Jakarta: Balai Pustaka.

\section{INTERNET}

Abhasshare.blogspot.com diakses tanggal 13 November 2014 pukul 22.00 WIT http://www.jayapurakab.go.id/ diakses tanggal 14 Juli 2014 pukul 10.00 WIT 